\title{
Epidemiologia da Esquistossomose Mansônica no Engenho Bela Rosa, Município de São Lourenço da Mata, Pernambuco, Brasil ${ }^{1}$
}

\section{Epidemiology of Mansonic Schistosomiasis in Bela Rosa Sugar Mill, Municipality of São Lourenço da Mata, Pernambuco, Brazil}

\author{
Constança S. Barbosa ${ }^{2}$ \\ Carlos B. da Silva ${ }^{3}$
}

BARBOSA, C. S. \& SILVA, C. B. Epidemiology of Mansonic Schistosomiasis in Bela Rosa Sugar Mill, Municipality of São Lourenço da Mata, Pernambuco, Brazil. Cad. Saúde Públ., Rio de Janeiro, 8 (1): 83-87, jan/mar, 1992.

Bela Rosa, a small sugar mill located in the county of São Lourenco da Mata, state of Pernambuco, is a typical sugar production unit of the large sugar cane belt along the humid and hot coast of northeast Brazil. The Bela Rosa's 370 inhabitants are living under very low social and economic levels. Known by its high prevalence rates for the disease, the region has been subjected to different types of control programs recently.

Using data from 1967 to 1986 plus those from an epidemiological cross-section survey carried out in 1989, the authors describe the evolutional tendency of schistosomiasis endemicity in the area.

Keywords: Schistosomiasis; Epidemiology; Prevalence Rates; Pernambuco; Brasil

O município de São Lourenço da Mata, distante $18 \mathrm{~km}$ ao norte da cidade do Recife, estado de Pernambuco, está localizado na microrregião conhecida como "Floresta Tropical da Encosta". A região é baixa e coberta, originariamente, por vegetação característica de floresta tropical. Essa mata tem sido sistematicamente destruída para dar lugar ao plantio da cana de açúcar, monocultura quase exclusiva da região. O clima é quente e úmido. A temperatura média anual é de $27^{\circ} \mathrm{C}$, com pequenas variaçōes entre as estações seca e chuvosa. Há um ciclo sazonal bem delimitado de chuvas que vai do período de março/abril a julho/agosto. Durante o resto do ano ocorrem precipi-

\footnotetext{
1 Trabalho financiado, em parte, pela Superintendència do Desenvol vimento do Nordeste (Sudene).

2 Estaçāo de Biologia Experimental do Centro de Pesquisas Aggeu Magalhães. Campus da Universidade Federal de Pernambuco, Recife, PE, 500730, Brasil.

${ }^{3}$ Fundação Nacional de Saúde. Avenida Rosa e Silua, s/n, Recife, PE, 50000, Brasil.
}

tações periódicas e de curta duração. A taxa pluviométrica anual nesta microrregião se situa em torno de $2.000 \mathrm{~mm}$.

A população rural se concentra nos engenhos de cana de açúcar, sendo praticamente dependente desta forma de produção monopólica.

Esta região é historicamente conhecida pelas altas taxas de prevalência humana para a esquistossomose. $O$ município possui diversas coleções de água doce, a maioria formada por afluentes dos rios Capibaribe e Tapacurá, com a presença de uma única espécie de caramujo transmissor, Biomphalaria straminea.

A área rural, cuja característica é o cultivo quase exclusivo da cana de açúcar, é subdividida em vários engenhos, que têm uma população flutuante condicionada aos períodos de plantação e colheita.

Sucessivos inquéritos coprológicos levados a termo na região têm mostrado altas taxas de infecção humana para Schistosoma mansoni. Pellon \& Teixeira (1950) relatam a taxa de prevalência de $60,8 \%$ para a cidade de São 
Lourenço da Mata. Barbosa et al. (1970), em estudo transversal para a população rural do município, detectaram a prevalência de $71 \%$. Investigação conduzida entre 1966 e 1974 (Barbosa \& Costa, 1981) para avaliação do uso exclusivo de moluscicida no controle da esquistossomose em área rural do município conseguiu reduzir a prevalência de $73,4 \%$ para $30,7 \%$ nos engenhos tratados, enquanto que uma redução menor $(71 \%$ para $40,6 \%$ ) foi observada nos engenhos não tratados, usados como área de comparação.

Em 1979, com a criação do Programa Especial de Controle da Esquistossomose (PECE), operacionalizado pela Sucam (Superintendência das Campanhas de Saúde Pública, Ministério da Saúde), a média das taxas de prevalência em São Lourenço da Mata passaram de 17,2\% para $11,5 \%$ em 1982. Entretanto, de acordo com o último inquérito feito pela Sucam, em 1986 , essas taxas subiram novamente para 24,8\%.

Este trabalho pretende avaliar a atual prevalência da esquistossomose mansônica em um dos engenhos da área rural de São Lourenço da Mata e compará-la com dados de literatura. A suscetibilidade experimental do caramujo transmissor (B. straminea) à infecção por S. mansoni foi também verificada e comparada com dados publicados por Barbosa \& Costa (1981), que detectaram $1,35 \%$ dos caramujos eliminando cercárias.

A área investigada foi o engenho Bela Rosa, que possui uma população fixa de $\mathbf{3 7 0}$ habitantes e cuja principal atividade econômica é o cultivo da cana-de-açúcar. Os moradores do engenho vivem, em sua maioria, em casas de taipa, sem qualquer infra-estrutura de saneamento básico. As crianças freqüentam uma escola local de $1^{\circ}$ grau e os habitantes não têm qualquer tipo de assistência médica permanente. A água utilizada para os diversos fins é coletada diretamente do rio Tapacurá, que corre ao lado das residências e é freqüentado assiduamente pela população local para banhos, lavagens de roupas, pescarias, etc.

A única campanha visando o controle da esquistossomose na localidade foi levada a termo durante o PECE. De acordo com os dados da Sucam, a população foi medicada com oxaminiquine quatro vezes: maio de 1979 (142 indivíduos), outubro de 1981 (412 indivíduos), junho de 1984 (250 indivíduos) e março de 1986 (117 indivíduos). A partir desta última data, nenhum outro tratamento foi realizado no engenho devido a prioridades de atendimento a outras campanhas.

De novembro de 1988 a dezembro de 1989 foram feitas oito coletas do caramujo $B$. straminea no rio Tapacurá, visando detectar a taxa de infecção natural desses moluscos para S. mansoni. Os caramujos foram coletados com conchas ou pinças em vários pontos do rio, especialmente nos lugares onde a água era represada para banhos e lavagens de roupas. Os caramujos foram levados ao laboratório, onde alguns exemplares foram dissecados para a confirmação da espécie através do exame do aparelho genital. O restante era exposto a iluminação artificial, em grupos de cinco, durante 60 minutos, após os quais eram examinados em microscópio estereoscópico para verificação da eliminação de cercárias. Após o primeiro exame, os moluscos foram mantidos em aquários e depois de 30 dias, submetidos a nova inspeção.

$\mathrm{O}$ inquérito coprológico foi realizado em toda a população na faixa etária de 7-14 anos, em um total de 105 indivíduos. Os exames parasitológicos foram processados no laboratório pela técnica de Hoffman para pesquisa de ovos de helmintos. Alguns aspectos ecológicos, como a co-ocorrência de outros tipos de moluscos e plantas aquáticas do criadouro, foram observados.

Foram capturados 8.300 caramujos $B$. straminea nas oito coletas de campo, realizadas nas diversas estaçōes do ano, não sendo encontrado nenhum caramujo eliminando cercárias de S. mansoni.

Além da abundância do molusco vetor, a presença de outros moluscos foi constatada nos criadouros, como Stenophysa sp e Pomacea sp. As plantas aquáticas (ou em contato com o criadouro) identificadas foram Eichornia azures, Pontederia chordata e Hetherantera reniforme, da família Pontederiaceae.

O levantamento coprológico da população estudada evidenciou uma alta prevalência para a esquistossomose, assim como para outras hel- 
mintoses. Os resultados dos 105 exames de fezes se encontram na Tabela 1.

TABELA 1. Taxas de Prevalência, Engenho Bela Rosa, São Lourenço da Mata, Pernambuco, 1989

\begin{tabular}{lc}
\hline \hline Helmintos & $\begin{array}{c}\text { Taxas de } \\
\text { Infecção }\end{array}$ \\
\hline Ascaris lumbricoides & $81 \%$ \\
Ancylostoma sp. & $32 \%$ \\
Schistosoma marsoni & $92 \%$ \\
Strongyloides stercoralis & $2 \%$ \\
Trichuris trichiura & $62 \%$ \\
\hline \hline
\end{tabular}

A Tabela 2 mostra as taxas de prevalência de acordo com dados de literatura de tres diferentes inquéritos.

Os individuos com resultado positivo para Schistosoma mansoni foram inquiridos sobre o seu local de origem. A conclusão foi a de que eram todos casos autóctones.

O engenho Bela Rosa constitui-se num sítio ideal para estudos de dinâmica de transmissão da esquistossomose mansônica devido às caracteristicas peculiares relativas aos aspectos sociais, econômicos e biológicos. Possui um criadouro permanente (rio Tapacurá) para o molusco transmissor e de fácil acesso para as atividades humanas, com alta densidade populacional de caramujos. Após a estação das chuvas, no período pós-inverno, o volume das águas do rio é consideravelmente reduzido.
Nessa época, os moradores do engenho costumam represar a água em diversos pontos do rio para facilitar as atividades domésticas e de lazer, formando largos remansos de águas rasas. Nesses locais, o caramujo vetor se reproduz abundantemente, encontrando condições ideais e apropriadas de fixação e alimentação. A presença de outros tipos de moluscos nos criadouros, como Stenophysa e Pomacea, parece não afetar a sobrevivência dos Biomphalaria, no sentido de disputa de recursos, por exemplo. Da mesma forma, não foi possível detectar nenhuma associação negativa entre os planorbídeos e a vegetação identificada nos criadouros e nas margens do rio.

Os resultados dos exames malacológicos, que mostraram os $8.300 \mathrm{~B}$. straminea negativos à infecção por $S$. mansoni, indicam que esta espécie se mantém como hospedeiro parcialmente resistente, apesar de sua longa co-evolução com o parasito.

Alćm da infeç̧ão por Schistosoma mansoni, as crianças apresentaram carga parasitária elevada para outras helmintoses, o que revela as precárias condições sanitárias da população, determinadas pelas condições sócio-econômicas e ausência de assistência à saúde.

$O$ fato da comunidade não ser beneficiada com qualquer infra-estrutura de saneamento básico provoca a interação necessária e obrigatória dos residentes com o único recurso hídrico disponivel. Esta interação está estreitamente incorporada à cultura da comunidade, que se utiliza da água do rio não só como necessidade vital, mas também como prática social de lazer.

TABELA 2. Evolução da prevalência da esquistossomose mansônica no Engenlıo Bela Rosa, São Lourenço da Mata, Pernambuco, de 1967 a 1989

\begin{tabular}{|c|c|c|c|c|c|c|c|c|c|c|c|}
\hline \multirow{2}{*}{$\begin{array}{l}\text { Dados } \\
\text { Avaliados }\end{array}$} & \multicolumn{11}{|c|}{ anos } \\
\hline & 67 & 72 & 73 & 74 & 76 & 78 & 79 & 80 & 82 & 86 & 89 \\
\hline prevalência (\%) & 89,5 & 42,3 & 44,0 & 28,9 & 35,5 & 34,3 & 31,3 & 21,5 & 45,0 & 83,8 & 92,0 \\
\hline$n^{8}$ exames & 458 & 284 & 461 & 287 & 245 & 254 & 92 & 242 & 80 & 117 & 105 \\
\hline fonte & $\star$ & * & * & * & * & * & ** & * & ** & $\star *$ & $\star \star \star$ \\
\hline
\end{tabular}

* dados formecidos por Felipe Gonçalves (Centro de Pesquisas Aggeu Magalhães)

** Sucam

*** O presente estudo 
Um dos fatores que asseguram a alta taxa de prevalência humana em localidades com essas características pode ser a elevada densidade populacional apresentada por $B$. straminea em certos períodos do ano. Como a frequiência do contato homem/água é contínua e intensa, alguns poucos caramujos eliminando cercárias poderiam garantir a infeç̧ão humana a tais níveis e a conseqüente manutenção do ciclo do parasito.

Com relação à Tabela 2 , observa-se uma progressiva redução nas taxas de prevalência entre 1967 e 1980, voltando a níveis preocupantes em anos mais recentes. A redução observada na década de 70 pode ser explicada pela proximidade de Bela Rosa coma as áreas tratadas com moluscicidas (Barbosa \& Costa, 1981), assim como pela influência da informação recebida através do contato de vizinhança com os engenhos próximos aonde se desenvolvia o programa de controle do vetor. É interessante observar que o tratamento quimioterápico em massa, utilizado pelo PECE, embora tenha apresentado efeitos iniciais promissotes sobre a prevalência, foi insuficiente para mantê-la em niveis toleráveis. Com a suspensão das medidas de controle, em 1986, a proporção de indivíduos infectados atingiu níveis hiperendêmicos nunca antes detectados em vinte anos de observações.

Esses fatos indicam que a efetividade dos métodos convencionais de controle da esquistossomose são limitados por numerosos fatores de ordem econômica e social. Os contínuos insucessos dessas intervenções unilaterais deixam a marca de sua ação poluidora nas reservas de água doce e efeitos tóxicos no organismo humano.

Barbosa (1983), ao propor soluções alternativas para o controle da endemia, considera que As doenças sócio-dependentes apresentam alguns complicadores que explicam todas as falhas que têm sido registradas nos esforços para combatê-las. Elas estão intimamente ligadas ao modo de viver da população, e a luta contra a mesma não depende somente da racionalização dos serviços de saúde, mas também, e principalmente, de um processo de mudança social e de um novo projeto econômico no qual as populações venham a participar intensa e conscientemente.

\section{AGRADECIMENTOS}

Os autores agradecem a Barnabé José Tabosa e Manoel Alexandre Neto (CPqAM-Fiocruz) pela assistência técnica. Ao Dr. Janduyr Moreira Leite (Faculdade de Filosofia do Recife) pela identificação das plantas aquáticas. Ao Dr. José Felipe Gonçalves (CPqAM-Fiocruz) e ao Dr. Ubiracy Guida (Fundação Nacional de Saúde) pelos dados de prevalência da esquistossomose. Ao Prof. Frederico Simões Barbosa (Ensp-Fiocruz) e ao Dr. Otávio Pieri (IOC-Fiocruz) pela leitura crítica deste manuscrito.

\section{RESUMO}

BARBOSA, C. S. \& SILVA, C. B. Epidemiologia da Esquistossomose Mansônica no Engenho Bela Rosa, Município de São Lourenço da Mata, Pernambuco, Brasil. Cad. Saúde Públ., Rio de Janeiro, 8 (1): 83-87, jan/mar, 1992.

Bela Rosa, um pequeno engenho localizado no município de São Lourenço da Mata, estado de Pernambuco, representa uma típica unidade produtora de açúcar situada na grande região da mata úmida do nordeste do Brasil. Os 370 habitantes do engenho vivem em niveis social e econômico muito baixos. A região é conhecida pelos seus elevados niveis de prevalência da esquistossomose e foi submetida nestes últimos anos a diferentes tipos de programas de controle da infecção. Utilizando dados de 1967 a 1986 e mais aqueles obtidos por um estudo epidemiológico transversal feito em 1989 , os autores descrevem a tendência evolutiva da endemicidade da esquistossomose na área.

Palavras-Chave: Esquistossomose; Epidemiologia; Taxas de Prevalência; Pernambuco; Brasil

\section{REFERÊNCIAS BIBLIOGRÁFICAS}

BARBOSA, F. S., 1983. Atuação dos serviços de saúde no controle das doenças endêmicas. $A$ Saúde no Brasil, 1: 198-20. 
BARBOSA, F. S. \& COSTA, D. P. P., 1981. A long term schistosomiasis control project with moluscicid in a rural area of Brazil. Annals of Tropical Medicine and Parasitology, 75: 41-52.

BARBOSA, F. S.; PESSOA, D.; PINTO, R. F.; BARBOSA, J. M. \& RODRIGUES, B. A., 1970. Levantamentos seccionais sobre a esquistossomose no Nordeste do Brasil, III. Estado de Pernambuco (município de São Lourenço da Mata). Revista da Sociedade Brasileira de Medicina Tropical, 4: 269-80.

PELLON, A. B. \& TEIXEIRA, I., 1950. Distribuição da esquistossomose mansônica no Brasil. Monografia da Divisão de Organização Sanitária, Rio de Janeiro: Ministério da Saúde. 